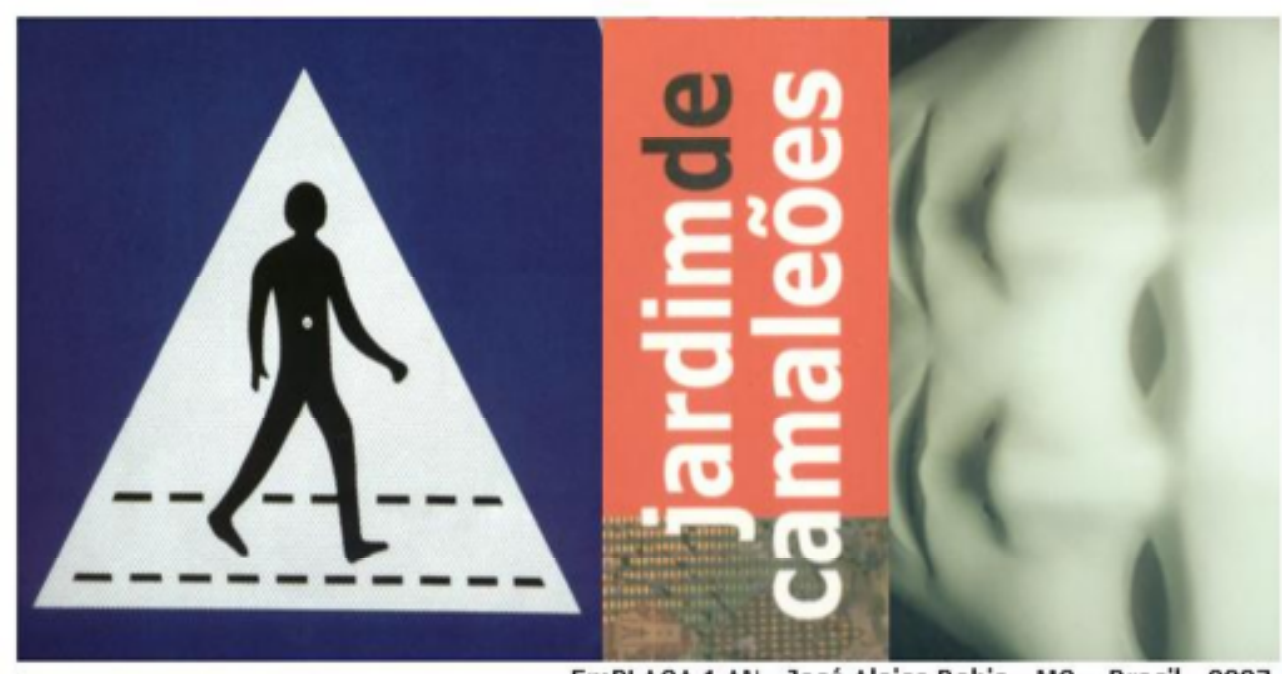

EmPLACA 1 AN - José Aloise Bahia - MG - Brasil - 2007

\title{
Série EmPLACA AN
}

José Aloise Bahia (Belo Horizonte, MG). Graduado em Economia/UFMG e em Comunicação Social/UNI-BH. Pós-graduado em jornalismo contemporâneo. Escritor e poeta. Autor de ensaios, resenhas, artigos, contos, crônicas, poemas e poesias visuais publicadas em jornais, revistas e sites do Brasil e do exterior. E-mail: josealoiselterra.com.br

O homem é um paradoxo intertextual de imagens. Cria, recria, e se apropria. Contempla, reflete. Refrata. Espanta-se, inquieta-se ou joga fora o que não lhe serve. Desorienta-se no reino da liberdade. Especula sem cessar...

Os meus poemas visuais são diálogos com as artes contemporâneas - gosto mais deste termo, no plural -, o (neo)dadaísmo, a arte conceitual, a pop art, o grafismo e - Movimento Neoísta: greve da arte da década de 1990.

Contes(X) tação sem nexo ou um surrealismo bestial. Muito mais = Simulacros híbridos, visuais virtuais interfaciais fabricados, desafio e reflexão em torno das questões da autoria e da autenticidade. A apropriação desloca parte de uma imagem já produzida dos seus contextos e suportes. Agrega a ela palavras, citações; uma, duas, três, no máximo quatro imagens diferentes também apropriadas no formato de feixe vertical/horizontal. Podem ter uma mensagem, uma narratibilidade $=$ Depende também do leitor. $O$ resultado $=\mathrm{A}$ 
produção de outra(s) imagem(ns) = Ou, uma imagem final correlacionando o encaixe das duas, três ou quatro que a formaram. Citando a artista plástica contemporânea = A italiana Vanessa Beecroft = "Estou interessado na diferença entre o que eu espero e o que realmente acontece".

As contemporaneidades são alegorias e justaposições conscientes e inconscientes de imagens queimando sem cessar as retinas e memórias. Cabe ao ser humano fazer as suas escolhas e leituras = Identificar-se com algo a mais, que o suplementa. Dialogar e construir narrativas que importam, e dar significados atuais que interessam na era da hipervisibilidade. E, seguir em frente...

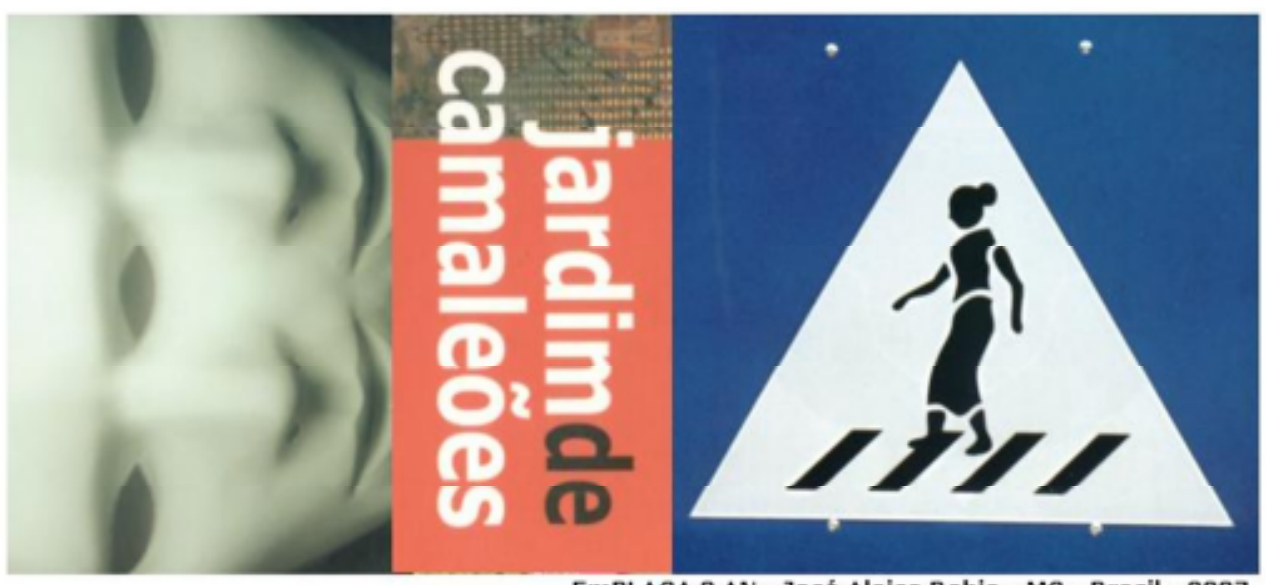

EmPLACA 2 AN - José Aloise Bahia - MG - Brasil - 2007
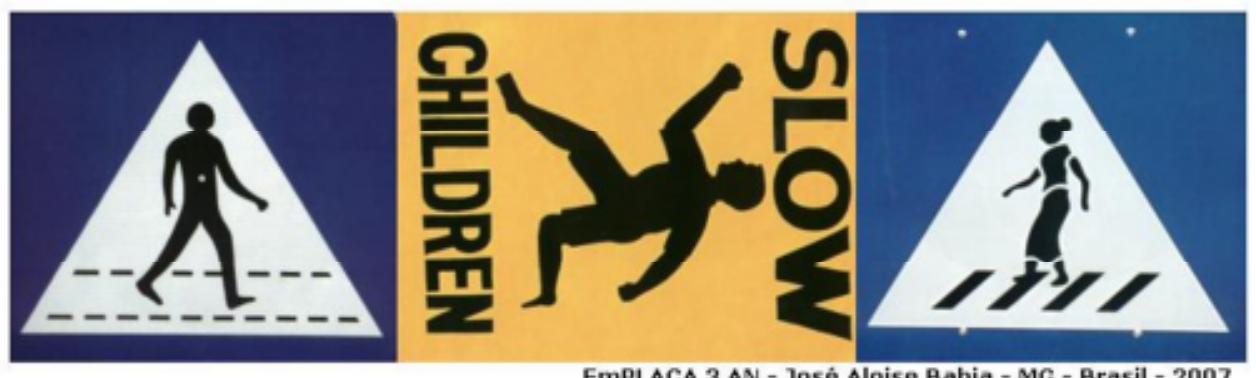

EmPLACA 3 AN - José Aloise Bahia - MG - Brasil - 2007

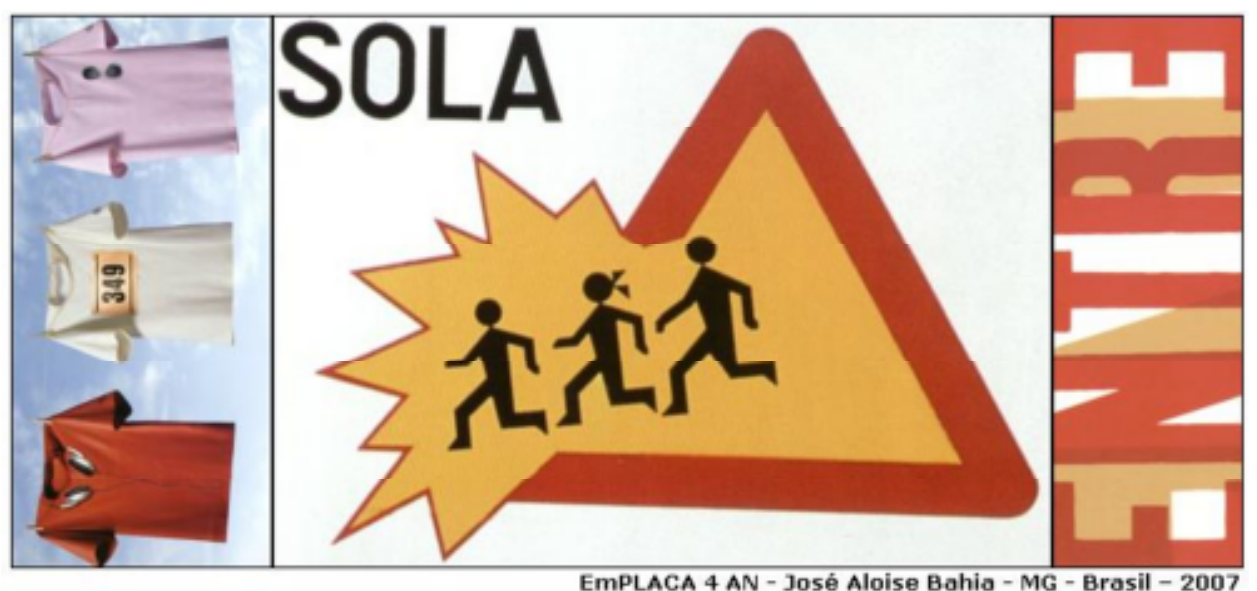




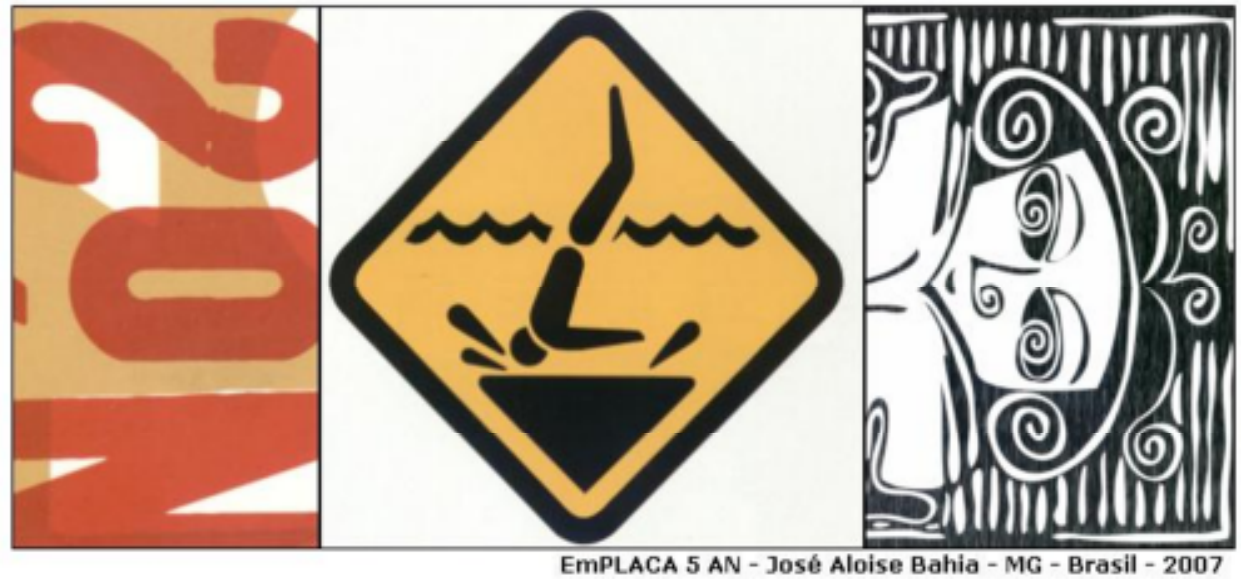

